\title{
A escola republicana francesa frente às exigências da lógica econômica: qual democracia? Entrevista com André D. Robert
}

Maria da Graça Jacintho Setton'

Rodrigo Pelegrini Ratier'

I- Universidade de São Paulo, São

\section{Resumo}

De um ponto de vista sociohistórico, é possível apreender as relações de correspondência existentes entre sistema econômico, Estado e escola. É a partir dessa perspectiva que André D. Robert, professor livre-docente da Universidade Lumière Lyon 2, empreende uma análise acerca do sistema escolar francês entre 1945 e 2014. A pergunta norteadora diz respeito à democratização em termos quantitativos e qualitativos. Ambição primeira do ideal republicano de escola, teria ela se tornado uma realidade efetiva no sistema escolar francês? $\mathrm{Na}$ entrevista, Robert recorre ao conceito de autonomia relativa para registrar a crescente submissão da escola à economia, nuançada pelo complexo jogo social dos atores envolvidos na definição e implementação das políticas escolares. Apresentando uma tipologia da escola francesa no período das sete últimas décadas, ele avalia o efeito de sucessivas reformas na função da escola na sociedade. Igualmente importantes são as considerações a respeito do papel da instituição escolar na contemporaneidade: estaria a educação duravelmente capturada pelo neoliberalismo? Observando uma reversão parcial nas políticas de desrresponsabilização estatal na administração François Hollande, Robert conclui pela existência, hoje, de uma escola a meio caminho entre os valores e práticas herdados da tradição republicana e as adaptações às exigências contemporâneas da lógica econômica. Um de seus observáveis é a emergência de uma democracia segregativa. Embora o acesso à escola seja cada vez menos dependente de variáveis como origem social, sexo, nacionalidade ou região geográfica, a hierarquia de distribuição dos alunos entre os cursos e oportunidades de ensino mais ou menos prestigiosas se encontra fortemente marcada pela origem social, característica que vem se acentuando nas primeiras décadas do século 21.

\section{Palavras-chave}

Reforma escolar - Escola republicana - Neoliberalismo Democratização escolar. 


\title{
French republican schools against economic logic constraints: which democracy? Interview with André $D$. Robert
}

\author{
Maria da Graça Jacintho Setton' \\ Rodrigo Pelegrini Ratier'
}

I- Universidade de São Paulo, São Paulo, SP, Brasil.

\begin{abstract}
From a sociohistorical point of view, one can understand correspondence relations between the economic system, state and school. It is from this perspective that André D. Robert, associate professor at the University Lumière Lyon 2, undertakes an analysis of the French school system between 1945 and 2014. The guiding question concerns the democratization in quantitative and qualitative terms. First ambition of the republican school model, has democracy become an effective reality in the French school system? In the interview, Robert uses the concept of relative autonomy to record the growing submission from school to economy, nuanced by the complex social game played by the actors involved in the definition and implementation of school policies. Featuring a French school typology of the last seven decades, the author evaluates the effect of successive reforms in the school's role in society. Equally important are the considerations about the role of the school in contemporary society: has education been lastingly captured by neoliberalism? Observing a partial reversal in the lack of state accountability during François Hollande's presidency, Robert concludes for the existence of a school model halfway between the values and practices inherited from the republican tradition and the adaptation to contemporary requirements of economic logic. One of his observables is the emergence of a segregative democracy. Although access to education is increasingly less dependent on variables such as social origin, gender, nationality or geographic region, the hierarchy of the distribution of students between courses and learning opportunities more or less prestigious is strongly marked by social origin, which has been increasing in the first decades of the 21 st century.
\end{abstract}

\section{Keywords}

School reform - Republican school - Neoliberalism - School democratization 


\section{Apresentação}

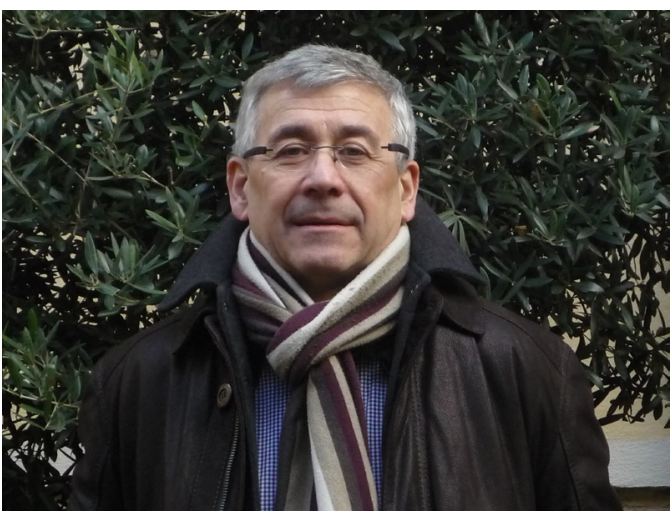

Crédito da foto: Ravena Olinda (doutoranda em filosofia na Universidade de São Paulo)

Desde 1998, André D. Robert é professor livre-docente da Universidade Lumière Lyon 2, em Lyon, França. É afiliado ao Institut des Sciences et Pratiques d'Éducation et de Formation (ISPEF), organização cujas origens remontam ao curso de ciências da educação da Faculté des Lettres de Lyon, um dos mais antigos da França, criado em 1884. No ISPEF, fundou em 2010 o laboratório de pesquisa Education, Cultures, Politiques, que conduziu durante dois anos. Dirige desde 2007 a école doctorale EPIC (Educação, Psicologia, Informação e Comunicação), que possui cerca de quatrocentos alunos de doutorado e dezenas de pesquisadores convidados - muitos dos quais brasileiros, chegados à França para períodos de doutorado-sanduíche, pós-doutorado e dupla titulação. Dos diversos convênios de cooperação existentes entre instituições brasileiras e o ISPEF de Lyon 2, muitos se concretizaram graças ao empenho pessoal do professor Robert. Em âmbito nacional, ocupou de 2011 a 2015 a presidência da seção de ciências da educação no Conseil National des Universités'.

Sua área-base de formação, a filosofia, disciplina que lecionou por duas décadas em

1- Organismo ligado ao Ministério da Educação da França, que tem por função regular as carreiras dos docentes de ensino superior, pronunciandose sobre questões relativas à qualificação, ao recrutamento e à promoção na carreira. diversos lycées $^{2}$ franceses, foi pouco a pouco dando lugar a abordagens sociohistóricas em sua trajetória de pesquisa. Seus principais trabalhos investigam políticas públicas em educação e o sindicalismo docente, com foco nas interações entre esses dois domínios. Nascem, assim, análises políticas dos sistemas educativos, estudos dos processos de tomada de decisão em políticas públicas de educação, reformas educacionais e seus efeitos, modelizações dos elementos em jogo nos processos de mudança dos sistemas educativos e investigações sobre a ação das forças sociais ao longo desses processos.

Autor de diversos livros, capitulos de obras coletivas e artigos científicos em língua francesa e inglesa, André D. Robert possui também escritos em português. São capitulos nos livros Associativismo e sindicalismo em educação: teoria, história e movimentos e Sindicalismo em educação e relações de trabalho - uma visão internacional (ROBERT, 2013; 2015b) e diversos artigos: Ainda é possivel falar de escola "à francesa"? Algumas reflexões sobre as politicas educacionais no contexto contemporâneo, traduzido por Alain François, com revisão técnica de Ivany Pino, para a revista Educação \& Sociedade (ROBERT, 2007), Gaulismo e capital humano, um novo paradigma escolar, traduzido por Maria Neves, com revisão científica de José Duarte para a Revista Lusófona de Educação (ROBERT, 2008), Um olhar sobre a obra de Jean-Claude Forquin: a Filosofia e a Sociologia da Educação (ROBERT, 2012), com tradução de Ana Nobre e revisão científica de Rosa Serradas Duarte, também para a Revista Lusófona de Educação, além de um diálogo com Manuel Tavares na mesma publicação - Crise e crítica da Educação: uma visão macroscópica e prospectiva. Princípios orientadores da formação de professores. Manuel Tavares conversa com André Robert (TAVARES, 2003).

Robert é um intelectual plural. Suas reflexões sobre o sistema educacional e as

2- Estabelecimentos do ensino secundário que conduzem ao bacharelado. A faixa etária presumida é de 16 a 18 anos. 
políticas que o constituem se iniciam a partir de uma perspectiva marcadamente marxista, de orientação althusseriana. Ao longo dos anos, como nos conta nesta entrevista, outros aportes passam a impactar sua trajetória de pensamento: da sociologia crítica francesa à sociologia do currículo britânica; da perspectiva foucaultiana sobre a ordenação e o controle da vida social à pós-modernidade performativa de Lyotard, chegando à admiração pela potência criativa do trabalho de renovação sociológica empreendido por Bruno Latour.

Seu livro mais recente, L'école em France: de 1945 à nos jours (ROBERT, 2015a), é uma edição ampliada de sua obra-referência de 2010. A ambição é mapear as mutações na função da escola francesa ao longo de sete décadas, período que se estende da liberação do jugo nazista no fim da Segunda Guerra Mundial (1939-1945) à atual legislatura. A publicação, em 2015, de uma segunda edição ampliada é bem-vinda, por ajudar a balizar os reais pontos de inflexão, em termos de política educacional, entre duas administrações de matizes ideológicos distintos: Nicolas Sarkozy, presidente por um partido de direita - o Union pour un Mouvement Populaire (UMP) atual Les Republicans - entre 2007 e 2012, e François Hollande, eleito pelo Partido Socialista (PS) com a promessa de "refundar" o sistema escolar. Interessa saber, nas palavras do autor, se a escola francesa estaria duravelmente capturada pelo neoliberalismo.

Tanto na França quanto na maioria dos países desenvolvidos, o período analisado se caracteriza, segundo Robert, pela intensificação da ligação entre a escola, a esfera econômica e o mercado de trabalho. Na fase mais recente do capitalismo, dita de mundialização e financeirização exacerbada, esse laço seria ainda mais determinante. Designando a relação pela expressão "captura da escola pela economia", André D. Robert alerta que não basta dizer, à moda de Baudelot e Establet (1971), que a uma

3- Saisissement de l'école par l'économie, no original em francês. economia capitalista corresponde uma escola que é orientada por esse sistema. Uma análise nuançada requer ter em conta o tipo de capitalismo em questão, o tipo de determinação de uma pela outra e as contradições internas que podem surgir, seja no que diz respeito a desigualdades relativas à origem social, gênero, seja em termos de relação formação/emprego. Assim:

\begin{abstract}
Sustentaremos o ponto de vista da dependência relativa da instituição escolar [...] em relação ao regime econômico, tendo presente a noção de autonomia relativa de um "campo", tal qual analisado por Pierre Bourdieu. Reservando-se o direito de interrogar, ao longo de seu desenvolvimento, as influências da economia - as formas de racionalidade política e as ideologias que a acompanham - sobre a evolução da instituição escolar francesa de 1945 a 2014, nossa obra não pretende recorrer de imediato a um qualificativo (capitalista, liberal, neoliberal ou outro) que encerre a análise. (ROBERT, 2015a, p. 7, tradução nossa)
\end{abstract}

Recorrendo a Patrice Duran (1999), o autor lança mão da noção de política escolar para qualificar e fornecer a real dimensão das mudanças observadas. Concretizadas na forma de leis, decretos e circulares que a administração escolar deve executar, as políticas escolares tornam mais visíveis as conexões entre economia, Estado e escola no fluxo permanente de transformações. A análise da natureza de cada uma das decisões - técnicas, filosóficas, deliberadamente políticas, influenciadas por atores do campo econômico etc. -, do grau de autonomia do legislador e do complexo jogo social entre os atores e instituições envolvidos (governo, sindicatos, sociedade civil organizada etc.) contribui para explicar o resultado das reformas e seu impacto efetivo na escola.

Sua tipologia da escola francesa é ilustrativa das mutações no papel da instituição ao longo desses setenta anos. A construção de cada 
um dos tipos e sua correspondência com um modelo de sociedade, na perspectiva de Durkheim (1969), é uma engenhosa inspiração para trabalhos em sociologia e história da educação. Ao período conhecido como "trinta gloriosos" (1945-1975) corresponderia uma escola que se pretendia moderna e democratizante, característica de um Estado de bem-estar social, promotora do ideal de igualdade de oportunidades e de possibilidades reais de promoção social.

Tal potencial presumido de libertação intelectual e de redução das desigualdades, contestado pela sociologia crítica desde o início dos anos 1960, passa por acentuada crise no período seguinte, jocosamente chamado por jornalistas franceses de "vinte lamentáveis" (1975-1995), a que corresponderia uma escola hesitante quanto aos métodos e às finalidades da educação. Há um questionamento crítico pontual de conceitos como estandardização, universalização e centralização, sem que se opere, porém, uma ruptura efetiva.

0 terceiro período (1995 em diante), correspondente à fase atual do capitalismo mundializado e de um Estado empresarial/ gerencial, apresenta uma escola incerta. 0 autor se interroga em que medida o avanço do gerencialismo e da cultura de performance acarretariam, no seio da instituição escolar, novas formas de socialização formativa, por oposição à forma escolar tradicional, na acepção de Vincent (1980).

0 balanço do período registra avanços e recuos. Robert classifica como "sucesso relativo" o passado recente do modelo de escola à francesa. Ela estaria situada "a meio caminho entre os valores e práticas herdados da tradição republicana e as adaptações às exigências ambientais contemporâneas, entre uma orientação cultural que comporta ainda uma

4- Termo criado pelo economista Jean Fourastié (1907-1990) para designar os trinta anos de reconstrução, modernização e expansão da economia francesa no pós-guerra, com efeitos benéficos no nível de vida dos franceses. forte dimensão crítica e a inscrição numa lógica econômica" (ROBERT, 2015a, p. 336, tradução nossa). Aponta-se a universalização do ensino e a generalização de trajetórias de escolarização cada vez mais alongadas. Estas seriam cada vez menos dependentes de variáveis como classe social, sexo, nacionalidade ou região geográfica. No entanto, o acesso às opções de estudo mais prestigiosas estaria crescentemente relacionado à origem social. Recorrendo aos dados levantados por Pierre Merle (2009) sobre o bacharelado terminal $\mathrm{S}^{5}$, Robert constata um recuo da presença de classes populares entre 1984-1985 e 2005-2006. A situação atual, portanto, poderia ser caracterizada como uma espécie de democratização segregativa. Num exemplo: filhos de operários possuem muito mais diplomas do ensino superior do que no passado, mas são ainda muito menos diplomados que filhos de executivos.

Supervisor do período de doutoradosanduíche de um dos entrevistadores, o professor André D. Robert teve a generosidade de responder longamente às perguntas enviadas por e-mail. Na interlocução, o professor apresenta os caminhos que o levaram à perspectiva sociohistórica que anima suas pesquisas e análises sobre o sistema escolar, fala sobre a importância da sociologia francesa contemporânea e sintetiza as linhas de força fundamentais que desembocam na configuração atual do sistema escolar francês.

Esperamos que a publicação desta interlocução ofereça não apenas elementos para a discussão dos aspectos que caracterizam o sistema educacional francês pós-Segunda Guerra, mas também insumos sociológicos e históricos para todos que desejarem compreender os desafios da instituição escolar no contexto contemporâneo de capitalismo globalizado, numa perspectiva relacional entre escola, Estado e sistema econômico.

5- Etapa preparatória para o bacharelado na série científica $\mathrm{S}$, a mais concorrida. 


\section{Referências}

BAUDELOT, Christian; ESTABLET, Roger. L'école capitaliste en France. Paris: Maspero, 1971.

DURAN, Patrice. Penser l'action publique. Paris: Librairie générale de droit et de jurisprudence, 1999.

DURKHEIM, Émile. L'évolution pédagogique en France. Paris: PUF, 1969.

MERLE, Pierre. La démocratisation de l'enseignement. Paris: La découverte, 2009.

ROBERT, André. Ainda é possível falar de escola "à francesa"? Algumas reflexões sobre as políticas educacionais no contexto contemporâneo. Educação \& Sociedade, v. 28, n. 98, p. 211-230, 2007.

ROBERT, André. Gaulismo e capital humano, um novo paradigma escolar. Revista Lusófona de Educação, v. 12, p. 29-40, 2008.

ROBERT, André. Um olhar sobre a obra de Jean-Claude Forquin: a Filosofia e a Sociologia da Educação. Revista Lusófona de Educação, n. 20, p. 157-171, 2012.

ROBERT, André. Os sindicatos de professores e a pesquisa em educação. Sobre alguns deslizes epistemológicos. In: GINDIN, Julián; FERREIRA, Márcia Ondina Vieira; ROSSO, Sadi dal (org.). Associativismo e sindicalismo em educação: teoria, historia e movimentos. Brasília: Paralelo 15, 2013.

ROBERT, André. L'école en France de 1945 à nos jours. Grenoble: Presses Universitaires de Grenoble, 2015a.

ROBERT, André. De 1968 à década de 2000: lutas por influência e posições cruzadas dos principais sindicatos de professores franceses (primário e secundário). In: ROSSO, S. Dal; FERREIRA, Márcia Ondina Vieira (org.). Sindicalismo em educação e relações de trabalho - uma visão internacional, pp. 45-64. Brasília: Paralelo 15, $2015 \mathrm{~b}$.

TAVARES, Manuel. Crise e crítica da Educação: uma visão macroscópica e prospectiva. Princípios orientadores da formação de professores. Manuel Tavares conversa com André Robert. Revista Lusófona de Educação, v. 2, 2003.

VINCENT, Guy. L'école primaire française. Lyon: PUL, 1980. 


\section{A ENTREVISTA}

Trajetória acadêmica e pensamento sociológico Entrevista com André Robert, Universidade Lumière Lyon 2

Conte-nos sobre sua formação acadêmica e trajetória profissional, onde o senhor estudou, qual foi seu ponto de partida, quais são suas principais atividades e sua posição atual no meio universitário francês.

Após o bacharelado, optei por não buscar imediatamente a universidade, mas por me preparar para os exames de entrada das grandes écoles. É uma peculiaridade francesa que o ensino superior seja dividido em dois ramos, o da universidade, para muitos, e o das grandes écoles, para um número menor de alunos. Meu objetivo era cursar sobretudo a École Normale Supérieure (ENS), em Paris. Como, ao fim de três anos, não consegui passar no difıcílimo exame de admissão, ingressei na Universidade de Lyon para realizar minha formação em filosofia. Fui impactado pelos cursos de Geneviève Rodis-Lewis, especialista em Platão, Bernard Bourgeois, um especialista em Hegel e Marx, e François Dagognet, filósofo e médico morto em 2015, autor de uma obra muito original, que pode ser situada na linha Bachelard, no campo da epistemologia.

$\mathrm{Na}$ segunda metade dos anos 1970, tornei-me professor de filosofia no ensino secundário, lecionando em vários lycées no oeste da França. Como militante político, atuei no principal sindicato francês de professores do ensino secundário, o Syndicat National des Enseignements de Second Degré (SNES) ${ }^{6}$, que existe ainda hoje. Do período dos lycées, guardo a lembrança de muitas aulas e alunos, alguns dos quais se tornaram meus amigos. Mas logo senti o desejo de mudar minha carreira. Não me enxergava lecionando por trinta anos na mesma escola. Passei em um concurso que me

6- Fundado em 1944, em Paris. conferiu o grau de professor agrégé7, o que me permitiu trabalhar com formação de professores. Lecionei psicopedagogia na área do ensino técnico-profissionalizante e me aproximei do departamento de Ciências da Educação da Universidade Paris V René Descartes. Lá conheci a socióloga Viviane Isambert-Jamati, que orientou minha tese de doutorado (ROBERT, 1989) e a de muitos doutorandos brasileiros, hoje professores universitários. Presto aqui um tributo às qualidades de seu trabalho científico, ao rigor na orientação de teses e também à sua grande benevolência e compreensão humana.

Em 1991, assumi meu primeiro cargo de professor universitário ao ingressar no Institut Universitaire de Formation des Maîtres (IUFM) de Créteil. Na época, tais institutos tinham sido criados recentemente para unificar a formação dos professores em todos os níveis (primário, secundário, profissional e técnico). Passei ainda pela Universidade de Rennes 2, defendi minha livre-docência (ROBERT, 1998) em Paris V, sob a orientação de Gabriel Langouet e, a seguir, fui recrutado pela Universidade Lumière Lyon 2, onde estou até hoje.

Em Lyon 2, fundei, em 2010, o laboratório de pesquisa Education, Cultures, Politiques, que conduzi durante dois anos. Dirijo, desde 2007, uma école doctorale pluridisciplinar e multiunidades, chamada Education, Psychologie, Information et Communication (EPIC). Meu papel é facilitar a vida administrativa e científica dessa estrutura, que reúne cerca de quatrocentos alunos de doutorado. Já recebemos diversos estudantes brasileiros para períodos de doutorado-sanduíche, pós-doutorado e dupla titulação.

Quais são os autores e/ou as escolas de pensamento que marcaram sua formação acadêmica?

Meu contexto de entrada no ensino superior era o final dos anos 1960, pós-maio

7- 0 mais elevado nível de carreira para os professores no ensino secundário francês. 
de 1968, quando a maioria dos estudantes era politizada. Eu mesmo me envolvi política e filosoficamente com o marxismo - marxismo ortodoxo no plano político e marxismo althusseriano no plano filosófico, este último um marxismo crítico que não chega a romper com o ideário do Partido Comunista. Fundamentalmente, fui influenciado pelo materialismo dialético, mas meus estudos de filosofia me levaram a estudar - e a apreciar - os grandes clássicos da filosofia política, como Platão, Aristóteles, Hobbes, Montesquieu, Rousseau, Hegel (sem ignorar os aportes de Descartes e Kant, e, na contemporaneidade, a corrente fenomenológica de Husserl, Sartre e Merleau-Ponty).

Aplicado à análise da escola, o pensamento de orientação marxista desenvolveu uma concepção crítica da escola burguesa como representante exclusiva dos interesses da classe dominante, totalmente alienadora e que, por isso, deveria ser combatida radicalmente. Encontramos um eco desse tipo de posição num Pierre Bourdieu que diz de forma lapidar: "Pode-se escrever, forçando-se o traço, que a 'escola libertadora' é o novo ópio do povo" (BOURDIEU, 1989, p. 164, nota de referência 2).

0 adjetivo libertadora se refere à ideia de que a escola, pelo simples fato de existir e independentemente de seu conteúdo ideológico, seria emancipatória, do ponto de vista do "povo". A história tem abundantemente demonstrado que não é assim. A escola republicana à moda de Jules Ferry ${ }^{8}$ serviu, de um lado, como suporte às iniciativas coloniais mais alienantes e, de outro, para ocultar a divisão da sociedade em classes e para reforçar a ordem social existente. Isso é o que a noção crítica de aparelho ideológico de Estado, criada por Louis Althusser (1976), nos possibilita perceber. Como todo filósofo marxista dos anos 1970 e 1980, fiquei impressionado com a potência analítica

8- Advogado, jornalísta e político francês, Jules Ferry (1832-1893) foi 0 Ministro da Educação (Instrução Pública, à época) mais influente da Terceira República francesa (1870-1940). Foi 0 autor das grandes leis escolares de 1881 e 1882. Foi titular do Ministério da Instrução Pública entre fevereiro de 1879 e setembro de 1880 e entre fevereiro e novembro de 1883. e a força pedagógica desse autor, pertencente ao Partido Comunista, capaz de combinar de maneira muito original as contribuições do marxismo e do estruturalismo.

Depois, como qualquer pesquisador francês em sociologia da educação, recebi a influência da sociologia crítica através de trabalhos marcantes de Pierre Bourdieu e JeanClaude Passeron, bem conhecidos no Brasil, Les héritiers: les étudiants et la culture (1964) e $L a$ reproduction (1970). Na demonstração implacável do papel fundamental da escola na reprodução da estrutura de classe das sociedades capitalistas, os dois sociólogos conclamam, na conclusão do primeiro livro, ao desenvolvimento de uma "pedagogia racional" para neutralizar a ação dos fatores sociais. Era uma posição mais dialética em relação ao escrito de Bourdieu que destaquei no início desta resposta. Também era algo com que minha concepção de marxismo se sentia mais de acordo. Na verdade, eu estava próximo de uma posição que consistia em extrair o "núcleo de verdade" da escola sob dominação burguesa, núcleo contido nos ensinamentos científicos e críticos (como os da filosofia) que não podíamos pura e simplesmente rejeitar, mas que deviam voltar-se contra a escola reprodutora. Tratava-se de trabalhar, de maneira dialética, as contradições internas da escola para fazê-la avançar a serviço da classe popular e, assim, contribuir para sua emancipação.

Uma importante etapa seguinte consistiu no encontro, por ocasião de minha tese de doutorado, com as posições da sociologia britânica da educação (representada por autores como Basil Bernstein, M. F. D. Young, R. Williams, G. Esland etc.). Ao contrário da sociologia francesa mais centrada na análise das estruturas (o que continua sendo uma passagem indispensável), a sociologia do currículo convida a penetrar na caixa-preta da escola, isto é, a fazer uma sociologia daquilo que se passa no interior das escolas e das salas de aula, uma sociologia dos atores. Na sua versão progressista, ela muda a perspectiva da 
luta contra o fracasso escolar, não a colocando unicamente na dependência de uma grande reforma estrutural (nunca realmente realizada ou nunca realizada sem efeitos perversos), mas relacionando-a com a ação pedagógica cotidiana de certos professores e com as políticas deliberadamente democratizantes de algumas escolas. Como diz o sociólogo Pierre Merle:

A democratização do ensino é [...] possível. Realiza-se aqui e ali em certas classes e certas instituições, nas quais se encontram reunidas as condições institucionais $\mathrm{e}$ pedagógicas propícias. (MERLE, 2009, p. 109, tradução nossa).

A hipótese de uma possível análise da história escolar pela noção de "forma escolar" constituiu uma nova etapa de minha reflexão. Meus trabalhos passam a se inserir mais deliberadamente no terreno da sócio-história. Refiro-me às publicações do sociólogo Guy Vincent (1980), que teorizou o conceito de forma escolar. A expressão completa - "forma escolar das relações sociais" introduziu a tese de que, na Europa, na virada do século XVI para o XVII, uma nova forma de socialização substitui outra, que abrangia um tipo socialização essencialmente prática, em que a aprendizagem se dava no trabalho e através da imitação. Contemporânea de uma nova concepção de infância, a relação pedagógica própria à forma escolar supõe um novo tipo de relacionamento entre um professor e alunos, um lugar específico dedicado à educação, uma repartição dos alunos por idades e por classes homogêneas e um modo de ensino preferencialmente simultâneo. Ao longo do século XIX, a forma escolar se concretiza na implantação de um espaço fechado para a aprendizagem dos alunos, de uma série de atividades em que o essencial é que elas exprimam a submissão a regras impessoais, em conformidade com uma organização do tempo cuidadosamente regrada por meio de uma progressão rigorosa ano a ano. Para Vincent, a forma escolar parece assim desenhada para o controle, a moralização, a disciplinarização da massa de jovens. Reconheço nessa análise uma inspiração geral de tipo foucaultiano, evocando mais particularmente o Foucault de Surveiller et punir (FOUCAULT, 1976) e seu conceito de panoptismo.

Finalmente, gostaria de compartilhar o espanto intelectualmente estimulante que foi o encontro com certas teses pósmodernas, mesmo se não compartilho a filosofia quando passam da constatação - a meu ver pertinente - ao programa - a meu ver contestável, pois sigo sendo um moderno. As previsões de Jean-François Lyotard em $L a$ condition post-moderne (1979) se configuram como tendências concretas quando ele evoca a instrumentalização e mercantilização do conhecimento na sociedade "do futuro" (ele fala dos anos 1970), ou seja, a sociedade neoliberal em que vivemos hoje. Num contexto em que o que importa é cada vez mais a performance, a competitividade e a rentabilidade, a questão relevante não é saber se algo é verdade, mas se é vendável, eficaz. De acordo com Lyotard, a deslegitimação do conhecimento concebido à moda antiga questiona o papel do professor e, em última análise, obriga a imaginar formas de socialização formativa esporádicas, parciais e em redes diferentes da escola ou da universidade. Não se permite mais pensar, por razões de fundo, o conceito de forma escolar das relações sociais envolvendo um professor sapiente, porque os bancos de dados agora supostamente equalizam a relação de todos com o saber. Para o autor, o caminho seria uma legitimação de novos conhecimentos pelas atividades de produção de diferenças criativas, da invenção imaginativa em vez de unificação e de coerência, atividades essas não ligadas por um desejo de consenso geral, mas apenas por consensos locais, temporários, sem visão de universalidade. Ainda que eu não compartilhe dessa visão como um programa, ela me instiga intelectual e civicamente. 
Como o senhor vê a influência da sociologia francesa no mundo hoje? Onde o senhor situaria a vanguarda da sociologia moderna, se é que ela existe?

São questões muito amplas e difíceis. Posso responder apenas parcialmente e com muita cautela. Quanto à primeira questão, respondo lembrando a existência e a influência da Association Internationale des Sociologues de Langue Française [Associação Internacional dos Sociólogos de Língua Francesa $]^{9}$. Além dos congressos anuais, grupos de trabalho temáticos se reúnem em diversos lugares no mundo. Quanto à questão da vanguarda, ressalvo a limitação de minha visão e o fato de que o próprio conceito de vanguarda está sujeito a controvérsias. Se entendemos vanguarda como algo emergente, devemos nos referir a obras que não tiveram ainda consagração definitiva, o que é missão quase impossível. Se considerarmos trabalhos consagrados há mais de vinte anos, eu me referiria aos estudos sempre inovadores e em curso de evolução permanente de Bruno Latour. Isso não quer dizer que eu partilhe de toda a filosofia, a antropologia e a sociologia desse pensador, que, a partir de seus trabalhos de sociologia das ciências (LATOUR, 1995; 2010), convidou-nos a repensar a sociologia e agora nos convida a pensar a política ecológica mundial (LATOUR, 2006; 2015). Mas sigo muito impressionado por sua potência criativa. Sociólogo político, ele nos exorta, sob o pano de fundo da urgência climática atual, a sair dos esquemas clássicos e a ouvir os "protestos dos oceanos, a revolta das terras, a indignação dos animais". Ele não hesita em publicar, além de artigos científicos e livros de estilo clássico, obras híbridas, combinando textos, conceitos e imagens - o que é consistente com sua teoria ator-rede, onde objetos, bem como os seres humanos, podem ser "atuantes". Uma referência é seu blog (www.bruno-latour.fr), muito inventivo.

9- Fundada em 1958, em Bruxelas.
Seu livro mais recente, L'école en France de 1945 a nos jours (2010, edição ampliada em 2015), apresenta uma visão sócio-histórica do sistema escolar francês ao longo de sete décadas. De que maneiras o período estudado nos aponta para uma transformação na função da escola?

Na França, desde as leis Ferry (1881$1882)^{10}$ até a Segunda Guerra Mundial (19391945), ou seja, antes do período que estudei, é possível falar de Estado ensinante ou Estado educador, e subscrever a análise de Bernard Charlot (1998) de que a função da escola é essencialmente "política, filosófica, moral, cultural”. Mais exatamente, o Estado educador cumpre uma função econômica apenas indiretamente: através da educação, ele pacifica a sociedade e garante a ordem necessária para a prosperidade econômica da burguesia.

Depois da Segunda Guerra, a escola é fortemente capturada pela economia em escala global, e esta é a característica das sete décadas que analiso. A partir de meados dos anos 1950, paralelamente a uma demanda exponencial para o ensino secundário por parte das famílias, perceptível na França mas também em muitos outros países, o ensino torna-se mundialmente (ao menos na esfera das nações desenvolvidas) um objeto de investigação econômica.

0 comparatista francês Le Than Khoi se permite falar de uma indústria do ensino (THAN KHOI, 1967). Uma teoria econômica assume a questão escolar, a teoria do "capital humano". Essa expressão deve ser entendida em oposição à de capital físico ou material, ou seja, os meios de produção ou "capital constante". Considerando o ritmo de desenvolvimento dos vários países na história econômica a longo prazo, certos pesquisadores são levados a constatar que o capital físico não tem um papel tão determinante no crescimento econômico como anteriormente se pensava, e que os três fatores de produção frequentemente

10- Conjunto de medidas que instituíram a obrigatoriedade do ensino entre 7 e 13 anos, a gratuidade e a laicidade da educação na França. 
mencionados (terra, capital, trabalho) não são suficientes para explicar o aumento do Produto Interno Bruto.

Os economistas inventam então a noção de "fator residual", pensado para englobar o progresso técnico, o crescimento do conhecimento, a qualificação da força de trabalho e o nível geral de instrução da população. Aos poucos, a maior parte, senão a totalidade desse fator residual, passa a ser dedicada à educação, devido ao fato de que a instituição escolar tem especificamente como missão acumular e transmitir conhecimentos que são condições de progresso técnico, um dos primeiros elementos de origem do crescimento econômico. As perguntas se tornam insistentes nas políticas públicas: se a educação é investimento - investimento no homem -, qual é seu rendimento em relação às outras formas de investimento? A que nível de rentabilidade o ensino contribui para o crescimento econômico de um país (entendendo que a teoria de referência assuma que há de fato contribuição)? Quais despesas um país deve dedicar à educação, e com quais modos de financiamento? Qual é a melhor "pirâmide educacional", ou seja, qual o número ideal de matrículas em diferentes níveis de ensino e em diferentes modalidades?

Como resultado desse tipo de orientação teórica, se a educação é o lugar de acumulação e transmissão dos conhecimentos necessários ao progresso técnico, parece que, nos países industriais avançados, as questões escolares são demasiado importantes para ser deixadas nas mãos de iniciativas arriscadas. Ao contrário, elas necessitam da intervenção de um Estado a serviço do crescimento e do lucro. Assim, uma reforma francesa de 1959 não hesita em falar, a respeito do esforço educacional empreendido pela nação, em "investir para o lucro máximo", o que significa esperar um retorno sobre o investimento na educação.

Um novo momento forte pode ser sentido por volta dos anos 2000, quando se opera uma alteração na natureza do capitalismo, passando-se de um capitalismo regulado, do tipo keynesiano (coincidindo com um estado de bem-estar social), a uma versão neoliberal, focada em menos Estado e menos despesa social (dá-se proeminência à concorrência e aos mercados). No plano educacional, quatro características distintivas podem ser destacadas internacionalmente, no que diz respeito à obrigação de resultados e de performance: novo paradigma político da escola como sistema de produção que olha para as entradas e saídas para medir o nível de desempenho e de eficiência; definição de indicadores que se tornam padrões, desenvolvidos por especialistas, e em relação aos quais é examinada a validade de uma política; papel central dos vários instrumentos de avaliação do desempenho dos alunos como medida de performance; estabelecimento de instrumentos de ação pública para produzir mudanças na escola, que giram em torno do conceito de accountability ou prestação de contas (MAROY, 2013).

A escola francesa não está imune a essa influência. A questão é se foi uma inflexão neoliberal completa, particularmente durante o governo de Nicolas Sarkozy (2007-2012). Minha resposta pessoal é nuançada: temos assistido a tentativas de transformar um sistema educativo muito fortemente regulamentado em um menos regulamentado ou até mesmo deliberadamente liberal. Tais tentativas atingiram seus limites na realidade em si - na força da tradição republicana francesa, na resistência dos movimentos sociais antiliberais, políticos e sindicais. Em linha com as políticas neoliberais, há menos envolvimento do Estado no financiamento da área. Essa lógica, contudo, foi interrompida com a mudança de governo em 2012.

De sua perspectiva de análise, é correto enxergar uma dependência relativa, em termos bourdiesianos, tanto do poder político quanto da instituição escolar aos regimes econômicos?

Nesse aspecto, sou durkheimiano: há correspondência entre a instituição escolar e a 
sociedade em que ela está inserida, o que inclui sobretudo o sistema econômico que caracteriza essa sociedade. Mas essa correspondência é relativa e não mecânica. Com efeito, não basta dizer "escola capitalista", como fizeram Baudelot e Establet (1971), para entender o que está acontecendo. Há vários determinantes que afetam a escola: econômicos, demográficos, ideológicos, relacionados a um conjunto de intervenções, provenientes de diversos atores sociais (partidos, grupos de interesse, famílias etc.) e cada vez mais de organismos prescritores internacionais (Comunidade Europeia, Organização para a Cooperação e o Desenvolvimento Econômico - OECD -, Banco Mundial etc.). Esses últimos estão na origem da exigência de requisitos de resultado e performance. Isso coloca a escola sob a influência da economia, é verdade, mas há também uma autonomia relativa no desenvolvimento de políticas escolares e da própria instituição (através do ministério e da sua administração e das administrações regionais e locais). Em outras palavras, na minha opinião, é preciso sempre ser dialético.

Há uma interessante tipologia da instituição escolar que estabelece uma correspondência das características da escola com as do Estado francês e as do sistema econômico em voga. Temos, assim, a escola conquistadora (19451975), a escola hesitante (1975-1995) e a escola incerta (1995-2005). 0 senhor poderia descrever cada um desses três tipos?

De fato tenho tentado fazer uma tipologia histórica dos setenta anos que nos separam da Liberação, o momento refundador de nosso país depois dos desastres da Segunda Guerra. 0 quadro geral é o de uma instituição de ensino capturada pela economia, mas três etapas podem ser distinguidas.

A primeira é o da escola confiante, conquistadora e democratizante. Esse é o período conhecido como "trinta gloriosos" (1945-1975), de acordo com a famosa frase do economista Jean Fourastié (1985). 0 estado de bem-estar se vê como modernizador e vai impulsionar a democratização do ensino secundário. Duas ondas de choque marcam o período: a ampliação do acesso ao primeiro ciclo do ensino secundário ${ }^{11}$ pelo efeito da demanda social (anos 1950) e a massificação dos collèges no âmbito de políticas voluntaristas (anos 1960 e 1970). Esses dois fenômenos determinam uma primeira explosão escolar nos primeiros níveis do ensino secundário.

A segunda etapa é a da escola hesitante, em que os princípios de justiça se multiplicam e, por vezes, entram em contradição entre si (por exemplo, o antigo princípio cívico republicano versus o novo princípio econômico, mercadológico), e em que as tarefas atribuídas à instituição escolar ampliam-se ao ponto de se tornarem confusas. Economicamente, esse é o período conhecido como "vinte lamentáveis"12 (1975-1995). Políticas escolares antitéticas emergem (entre direita e esquerda, e dentro da própria esquerda quando ela está no poder), contribuindo para a sensação de hesitação. No entanto, a democratização continua: há um terceiro choque, o da massificação dos lycées e do ensino superior (fim dos anos 1980 e anos 1990). É a segunda explosão escolar.

Na terceira etapa (desde aproximadamente 1995), a escola resolutamente se torna incerta, num mundo ele mesmo cada vez mais incerto. 0 estado é tentado pelo neoliberalismo e aqui chegamos à questão da instauração de uma escola que coincide com a introdução de uma nova forma de organização da sociedade neoliberal. Essa escola se torna também neoliberal, ainda que seus fundamentos republicanos históricos resistam, sobretudo graças à mobilização das partes interessadas (movimentos sociais e sindicatos)? Os sinais de neoliberalismo existem. São particularmente sensíveis a partir de 2002 e, especialmente,

11- Etapa correspondente ao collège (11 a 15 anos).

12- "Vingt piteuses", no original em francês. Expressão cunhada por jornalistas como eco ao termo "trinta gloriosos", de Fourastié. 
entre 2007 e 2012. Entretanto, o basculamento total não ocorreu.

O senhor afırma que o regime econômico atual encontra um de seus pilares de sustentação na equivalência entre quatro registros diferentes: educação, formação, qualificação e emprego. É possível falar numa naturalização da ideia de educação como preparação para a inserção no mercado de trabalho? Como se produz esse efeito de discurso e o que ele oculta?

Esse ponto se junta à constatação de que a escola foi definitivamente capturada pela economia nas últimas sete décadas. Cito a socióloga contemporânea Lucie Tanguy (1986; 2016), que acredita que a substituição frequente da palavra educação por formação representa mais do que apenas uma deriva semântica, mas uma verdadeira mutação política, colocando as preocupações relativas ao emprego no coração do sistema educativo. Isso não é um mal em si, desde que: a) tais preocupações não sejam exclusivas; b) não se considere um único modelo econômico (o capitalismo neoliberal); d) um espaço fundamental seja concedido à construção, em todos os alunos, de uma verdadeira cultura em relação às realidades contemporâneas, com uma dimensão crítica indispensável (correspondente ao significado amplo de educação).

Se estabelecermos relações de equivalência simples entre os quatro registros diferentes (educação, formação, qualificação e emprego), mascaramos o fato de que a formação é apenas uma parte da qualificação e esta é definida pelo mercado de trabalho e pelas empresas. 0 uso quase universal das noções de "relação formação/emprego" (no plural, como no singular) ou de "nível de formação" obscurece as relações sociais que lhes são subjacentes.

Essa fala de Lucie Tanguy é bastante crítica da situação atual e de um processo de “naturalização”. Naturalização designa aqui o processo discursivo que, ao substituir educação por formação (sob o ponto de vista exclusivo do emprego), apresenta-se como uma evidência que obriga a repartição dos formados no mercado de trabalho, revelando que se trata efetivamente de escolhas político-econômicas, como se esses jovens estivessem predestinados a determinados postos de trabalho devido às suas próprias "naturezas", sem lhes dar a menor chance de fazer de outra forma.

Trabalhei recentemente nas propostas antigas, mas inovadoras, do sociólogo Pierre Naville (1972). Ele desenvolveu uma crítica do funcionamento de classe, no sentido marxista, do sistema educativo e da concepção e da orientação que lhe são concomitantes. Para ele - como para Lucie Tanguy depois dele -, o recurso à ideia de disposições individuais vistas como congeladas, "naturais" (“dons"), serve para mascarar os mecanismos de seleção social da orientação escolar, em detrimento das populações mais desfavorecidas em capital social e cultural.

Entre a primeira e a segunda edição de seu livro (2010 e 2015), assistimos à subida ao poder de um governo de esquerda (François Hollande - Partido Socialista). No que diz respeito ao sistema escolar, em que medida o governo Hollande tem significado uma inflexão à deriva neoliberal promovida pelo governo de Nicolas Sarkozy?

Sob a presidência de Hollande, o Ministério da Educação tentou tomar o contrapé da orientação anterior. 0 objetivo é implementar uma "refundação" da escola francesa. Houve algumas marcas concretas na realidade. De 2012 até $1^{\circ}$ de setembro de 2014, foram criados 24.666 empregos no setor educacional (a promessa é de 60.000), enquanto, sob a presidência Sarkozy, 70.700 tinham sido removidos. 0 orçamento do Ministério da Educação aumentou em 422 milhões de euros. Globalmente, portanto, não estamos mais numa configuração de ideologia neoliberal que suponha uma redução do financiamento 
público como meio de reforma e de melhora do sistema.

No entanto, o Ministério não conseguiu ir ao fundo da lógica de refundação. Muitas reformas não produziram o efeito que se poderia esperar, apesar de alguns progressos. Por exemplo, as reformas do tempo escolar, da nova formação de professores, do ensino superior, da educação de primeiro grau, todas foram decepcionantes. Atualmente, a reforma dos collèges tem originado uma forte oposição de uma parte dos professores (incluindo os de esquerda).

O livro termina com um balanço agridoce sobre a escola francesa. 0 senhor recorre a Pierre Merle para afirmar a conquista de democratização, ainda que seja uma "democratização segregativa”. Poderia desenvolver um pouco essa noção? Em que medida a trajetória do sistema escolar francês lhe parece especifica dentro do contexto internacional?

A publicação do resultados da edição de 2012 do Programme for International Student Assessment (PISA) ${ }^{13}$ revelou a situação preocupante das escolas franceses: uma ligeira recuperação em francês, uma baixa em matemática e sobretudo - insisto - um crescimento constante das desigualdades entre os melhores alunos e os mais frágeis, em relação aos resultados anteriores. Esse último aspecto é muito grave, porque, se a democratização quantitativa é inegável ao longo dos últimos setenta anos, a democratização qualitativa, que teve progresso sensível entre 1945 e 1980, diminui desde cerca de 1980-1990.

Por democratização quantitativa entendemos o acesso de um número crescente de jovens de todas as classes sociais a um nível de estudo e de certificação cada vez mais alto. Esse é o caso para o bacharelado (diploma de fim de estudos secundários): em 1950, cerca de 10\% de

13- Em português, Programa Internacional de Avaliação de Estudantes, avaliação internacional trienal, conduzida pela Organização para a Cooperação e Desenvolvimento Econômico (OCDE), que mede competências de alunos de 15 anos em matemática, ciências e língua em 65 países e megalópoles (Xangai). uma geração o alcançavam, 30\% o faziam no início dos anos 1980 e cerca de 65\% hoje (na sequência de reformas, notadamente a criação de um bacharelado profissional em 1985).

Para a democratização qualitativa, dizemos que ela se adquire se o acesso aos estudos é cada vez menos dependente de variáveis como meio social, gênero, nacionalidade ou origem geográfica. Se a noção de democratização qualitativa nos encoraja a olhar para como se opera a distribuição dos alunos por percursos de escolarização, cursos e instituições escolares em função de suas classes sociais de origem, somos conduzidos a reconhecer desigualdades sociais marcantes e, especialmente, o aumento dessas desigualdades em relação a um período anterior - considerando que percursos de escolarização, cursos e instituições escolares são socialmente hierarquizados e possuem valor desigual no mercado de trabalho. Tendo em mente o exemplo do bacharelado: enquanto filhos de executivos e de professores estão majoritariamente na série $S$ (série científica seletiva), os filhos de operários e de empregados frequentam sobretudo o bacharelado profissional, o menos valorizado. Esses estudantes, vindos de grupos populares ou desfavorecidos, são mais numerosos nos percursos de escolarização tidos como menos prestigiosos. Isso é o que Pierre Merle (2009) chama, com precisão, de "democratização segregativa": ela ocorre no plano quantitativo (mais alunos com trajetórias escolares mais longas), mas é segregada no sentido de que no nível dos estudos mais prestigiados e socialmente valorizados, as diferenças de frequência e de sucesso escolar crescem em benefício dos estudantes vindos de classes sociais dominantes.

0 mesmo raciocínio se aplica do ponto de vista de gênero: enquanto as meninas se saem melhor do que os rapazes no bacharelado e nos primeiros anos de ensino superior, elas obtêm menos diplomas de engenheiro ou nas grandes écoles mais prestigiosas. Há, assim, um teto de vidro que proíbe a determinados sujeitos - em função de suas características iniciais - 
alcançar os níveis mais altos de ensino. Daí a segregação no interior da educação.

Um tema central em seus trabalhos são as reformas escolares. Ao analisar as dificuldades para concretizá-las efetivamente, o senhor descreve o complexo jogo de atores sociais conselhos de educação, sindicatos, docentes - que dá a impressão de imobilismo e de impossibilidade de qualquer reforma proposta pelo Estado. A que se deve essa aparente fragilidade do poder político mesmo em um Estado altamente centralizado como o francês? É possivel descrever as características das reformas mais bem-sucedidas - ou, para dizer de outra forma, das menos mal sucedidas?

Podemos definir política pública, conforme Duran (1999), como o produto de um processo social, que se desenrola num determinado período, num contexto que delimita o tipo e o nível de recursos disponíveis através de esquemas interpretativos e da escolha de valores que definem a natureza dos problemas públicos colocados e as orientações para a ação.

A ênfase na noção de processo social convida a incluir na noção de política escolar não apenas as ações concernentes às instituições escolares, conduzidas em nome de uma maioria parlamentar, por um governo e seu ministro da educação, mas também o envolvimento de vários grupos de interesse - sindicatos de professores em primeiro plano. Esses grupos, que desenvolvem posições que vão do protesto reativo simples à defesa de reformas coerentes e ambiciosas, participam da construção de uma política educacional característica de um determinado período. Define-se, portanto, uma cena ou arena na qual interesses concorrentes se confrontam e podem influenciar a vontade de quem está no poder. Num contexto de regime democrático e de um estado ainda centralizado, os responsáveis por esse poder não podem em nenhum caso ignorar o jogo desses atores sociais na implementação de seus projetos reformistas, seja por antecipação e precaução (especialmente via negociações realizadas dentro das instâncias de regulação instituídas), seja por coerção, sob a pressão de protestos, greves e outros movimentos. Isso pode realmente levar à impressão de imobilismo, de impossibilidade de qualquer reforma ou de resolução dramática, necessariamente parcial e insatisfatória. $\mathrm{Na}$ França, há muitos exemplos de grandes projetos de reforma, particularmente em relação ao collège, que não puderam ser implementadas em razão de oposições centrais (reforma do collège de 1982) ou que foram realizadas de forma muito empobrecida em relação à sua ambição inicial (reforma Haby ${ }^{14}$, de 1975). A hipótese é que, nos modos mais descentralizados de organização política, a regulação ao nível local facilita a gestão de mudanças (por exemplo, na região, no departamento ou no município). Mas a verdade é que, pelo menos na França, as mudanças tratadas nesses níveis decisórios são menores e não correspondem ao que é chamado de reformas no sentido pleno.

Como o senhor analisa os estudos atuais acerca da questão da escola em países democráticos?

Um dos livros mais influentes parece-me ser L'inflation scolaire: les désillusions de la meritocratie, de Marie Duru-Bellat (2006). Ela investiga o fenômeno contemporâneo, presente em todas as sociedades desenvolvidas e estudados por ela por meio do caso francês, da extensão contínua da duração dos estudos para um número crescente de jovens (a "sobre-educação" ou o que chamo de "pedagogização" da sociedade) e o declínio contínuo da rentabilidade dos diplomas na própria medida de seu crescimento. Esse fenômeno tem um impacto duplo: muda o significado dos estudos (cuja espontaneidade desinteressada é cada vez mais relegada em favor de uma noção de rentabilidade) e cria frustração na medida em que o diploma não permite uma verdadeira integração no mercado

14- Reforma que institui o collège único - reorganização das divisões de alunos segundo princípios heterogêneos, sem divisão entre as elites e os outros. 
de trabalho - quando permite, essa se dá sob a forma de "desclassificação". Consequentemente, é urgente repensar profundamente a organização da formação e do processo de integração social das jovens gerações, mas sem dúvida também o mundo do trabalho e aspectos da própria sociedade, uma vez que obviamente nem tudo depende da escola. No fundo, a questão que se coloca é de como repartir e pagar as diferentes posições na divisão do trabalho. Em sua conclusão, com base em constatações científicas, Marie Duru-Bellat preconiza a manutenção da meritocracia como "mito necessário" (talvez menos injusto do que outros dispositivos, apesar de suas ilusões e fragilidades): a ideia de que os melhores lugares da escola e os melhores postos sociais são dependentes de méritos de indivíduos, independentemente de outras considerações.
Mas ela também apela para o afrouxamento da concorrência entre os indivíduos, ao menos no início da escolarização, em favor de uma intenção deliberadamente cultural e benevolente da escola (como acontece, por exemplo, nas séries iniciais nos países nórdicos). Ela recomenda também a pluralização dos critérios de seleção explícitos de estudantes, reiterando a importância que atribui a uma política qualitativa do conteúdo cultural, em vez de uma política apenas de metas de desempenho, de acordo com a atual tendência internacional da escola de performance que já mencionei. E novamente cito aqui o trabalho de Christian Maroy (2013), que aborda de modo científico e crítico a situação educacional de muitos países do mundo submetidos à obrigação de resultados e à corrida pela performance (Bélgica, França, Israel, Suiça, Hungria, Canadá).

\section{PRINCIPAIS OBRAS DO ENTREVISTADO}

\section{Publicações em língua portuguesa}

ROBERT, André. Ainda é possível falar de escola "à francesa"? Algumas reflexões sobre as políticas educacionais no contexto contemporâneo. Educação \& Sociedade, v. 28, n. 98, p. 211-230, 2007.

ROBERT, André. De 1968 à década de 2000: lutas por influência e posições cruzadas dos principais sindicatos de professores franceses (primário e secundário). In: ROSSO, S. dal; FERREIRA, M.O.V. (org.). Sindicalismo em educação e relações de trabalho - uma visão internacional, p. 45-64. Brasília: Paralelo 15, 2015.

ROBERT, André. Gaulismo e capital humano, um novo paradigma escolar. Revista Lusófona de Educação, v. 12, p. 29-40, 2008.

ROBERT, André. Os sindicatos de professores e a pesquisa em educação. Sobre alguns deslizes epistemológicos. In: GINDIN, J; FERREIRA, M.O.V.; ROSSO, S. dal (org.). Associativismo e sindicalismo em educação: teoria, historia e movimentos. Brasília: Paralelo 15, 2013.

ROBERT, André. Um olhar sobre a obra de Jean-Claude Forquin: a Filosofia e a Sociologia da Educação. Revista Lusófona de Educação, n. 20, p. 157-171, 2012.

TAVARES, Manuel. Crise e crítica da Educação: uma visão macroscópica e prospectiva. Princípios orientadores da formação de professores. Manuel Tavares conversa com André Robert. Revista Lusófona de Educação, v. 2, 2003.

\section{Livros}

GAUTHIER, Roger-François; ROBERT, André. L'école et l'argent. Quels financements pour quelles finalités? Paris: Retz, 2005.

ROBERT, André. Actions et décisions dans l'Education nationale, un itinéraire de recherche. Paris: L'Harmattan, 1999.

ROBERT, André. L'école en France de 1945 à nos jours. Grenoble: PUG, edição ampliada 2015. 
ROBERT, André. Le syndicalisme des enseignants (écoles, collèges, lycées). Paris: La Documentation Française/CNDP, 1995. ROBERT, André. Miroirs du syndicalisme enseignant. Paris: Nouveaux Regards Syllepse, 2006.

ROBERT, André. Système éducatif et réformes (1944-1993). Paris: Nathan, 1993.

ROBERT, André; BOUILLAGUET, Annick. L'analyse de contenu. Collection Que-sais-je?. Paris: PUF, 1997.

ROBERT, André; ESPINOSA, Julieta. (coord.). Pensar la educación de otra manera: epistemologia social y pensamiento crítico. México: Juan Pablos Editor, 2014.

ROBERT, André; GARNIER, Bruno. (org.). La pensée critique des enseignants. Eléments d'histoire et de théorisation. Mont-StAignan: PURH, 2015.

ROBERT, André; TERRAL, Hervé. Les IUFM et la formation des enseignants aujourd'hui. Paris: PUF, 2000.

ROBERT, André; ZANTEN, Agnès van (org.). GROSPIRON, M-F; KHERROUBI, M. Quand l'école se mobilise. Paris: La Dispute, 2002.

\section{Referências}

ALTHUSSER, Louis. Idéologie et appareils idéologique d’État. Positions, 1964-1975, p. 67-125, 1976.

BAUDELOT, Christian; ESTABLET, Roger. L'école capitaliste en France. Paris: Maspero, 1971.

BOURDIEU, Pierre. La noblesse d'État: grandes écoles et esprit de corps. Paris: Minuit, 1989.

BOURDIEU, Pierre; PASSERON, Jean-Claude. La reproduction. Élements pour une théorie du système d'enseignement. Paris: Minuit, 1970.

BOURDIEU, Pierre; PASSERON, Jean-Claude. Les héritiers: les étudiants et la culture. Paris: Minuit, 1964.

CHARLOT, Bernard. L'école et le territoire: nouveaux espaces, nouveaux enjeux. Paris: Armand Colin, 1998.

DURAN, Patrice. Penser l'action publique. Paris: Librairie générale de droit et de jurisprudence, 1999.

DURKHEIM, Émile. L'évolution pédagogique en France. Paris: PUF, 1969.

DURU-BELLAT, Marie. L'inflation scolaire: les désillusions de la méritocratie. Paris: Seuil, 2006.

FOUCAULT, Michel. Surveiller et punir: Naissance de la prision. Paris: Gallimard, 1976.

FOURASTIÉ, Jean. Les trente glorieuses ou la révolution invisible de 1946 à 1975. Paris: Hachette, 1985.

LATOUR, Bruno. Changer de société, refaire de la sociologie. Paris: La Découverte, 2006.

LATOUR, Bruno. Cogitamus: six lettres sur les humanités scientifiques. Paris: La Decouverte, 2010.

LATOUR, Bruno. Face à Gaïa: huit conférences sur le nouveau régime climatique. La Découverte, 2015.

LYOTARD, Jean-François. La condition post-moderne: rapport sur le savoir. Paris: Minuit, 1979.

LATOUR, Bruno. La science en action: introduction à la sociologie des sciences. Paris: La Découverte, 1995.

MAROY, Christian. L'école à l'épreuve de la performance: les politiques de régulation par les résultats. Louvain-la-Neuve: De Boeck, 2013.

MERLE, Pierre. La démocratisation de l'enseignement. Paris: La découverte, 2009. 
NAVILLE, Pierre. La théorie de l'orientation professionnelle. Paris: Gallimard, 1972.

ROBERT, André. L'école en France de 1945 à nos jours. Grenoble: Presses Universitaires de Grenoble, 2015.

ROBERT, André. Politiques publiques d'éducation et actions collectives des enseignants. Tese de livre-docência. Université René Descartes Paris V - Sorbonne, 1998.

ROBERT, André. Trois syndicats d'enseignants face aux réformes scolaires: positions idéologiques du SNI, du SNES et du SGEN par rapport au système d'Education nationale entre 1968 et 1982, essai d'interprétation. Tese de doutorado. 1989. Paris 5.

TANGUY, Lucie. Enseigner l'esprit d'entreprise à l'école: Le tournant politique des années 1980-2000 en France. Paris: La dispute, 2016.

TANGUY, Lucie. L'introuvable relation formation-emploi. Paris: La Documentation française, 1986.

THANH KHOI, Le. L'industrie de l'enseignement. Paris: Minuit 1967.

VINCENT, Guy. L'école primaire française. Lyon: PUL, 1980. 